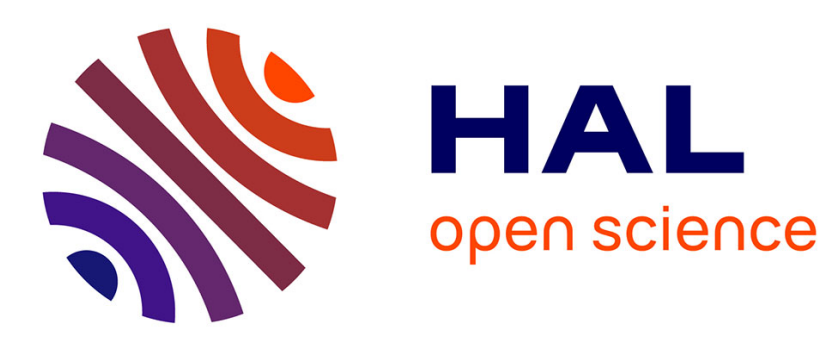

\title{
Photoelectrochemical study of nickel base alloys oxide films formed at high temperature and high pressure water
}

\author{
Loic Marchetti, Stéphane Perrin, Yves Wouters, Michèle Pijolat
}

\section{To cite this version:}

Loic Marchetti, Stéphane Perrin, Yves Wouters, Michèle Pijolat. Photoelectrochemical study of nickel base alloys oxide films formed at high temperature and high pressure water. Electrochimica Acta, 2010, 55 (19), pp.5384-5392. 10.1016/j.electacta.2010.04.063 . hal-00492837

\section{HAL Id: hal-00492837 \\ https://hal.science/hal-00492837}

Submitted on 17 Jun 2010

HAL is a multi-disciplinary open access archive for the deposit and dissemination of scientific research documents, whether they are published or not. The documents may come from teaching and research institutions in France or abroad, or from public or private research centers.
L'archive ouverte pluridisciplinaire HAL, est destinée au dépôt et à la diffusion de documents scientifiques de niveau recherche, publiés ou non, émanant des établissements d'enseignement et de recherche français ou étrangers, des laboratoires publics ou privés. 


\title{
Photoelectrochemical study of nickel base alloys oxide films formed at high temperature and high pressure water
}

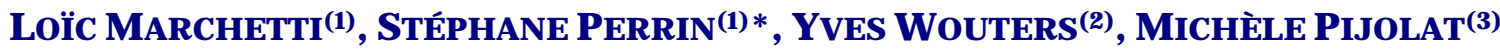

(1) CEA ; DEN ; DPC ; SCCME ; Laboratoire d'Etude de la Corrosion Aqueuse ; F-91191 Gif-sur-Yvette ; France

(2) SIMaP ; CNRS/INP-Grenoble/UJF F-384O2 ; Saint Martin d'Hères Cedex ; France

(3) Ecole Nationale Supérieure des Mines de Saint Etienne ; Centre SPIN ; Département ProcESS ; LPMG-UMR CNRS 5148 ; 158 Cours Fauriel ; 42023 Saint-Étienne Cedex 2 ; France

\begin{abstract}
The oxide film formed on nickel base alloys at high temperature and high pressure water exhibits semi-conducting properties evidenced by photocurrent generation when exposed to monochromatic light. The use of macro- and micro-photoelectrochemical techniques (PEC and MPEC) aims to identify the different semiconductor phases and their distribution in the oxide film.

Three different nickel base alloys were corroded in recirculation loop at $325{ }^{\circ} \mathrm{C}$ in pressurised water reactor primary coolant conditions for different exposition durations.

PEC experiments on these materials enable to obtain macroscopic energy spectra showing three contributions. The first one, with a band gap around $2.2 \mathrm{eV}$, was attributed to the presence of nickel hydroxide and/or nickel ferrite. The second one, with a band gap around $3.5 \mathrm{eV}$, was attributed to $\mathrm{Cr}_{2} \mathrm{O}_{3}$. The last contribution, with a band gap in the range of 4.1$4.5 \mathrm{eV}$, was attributed to the spinel phase $\mathrm{Ni}_{1-x} \mathrm{Fe}_{x} \mathrm{Cr}_{2} \mathrm{O}_{4}$. In addition, macroscopic potential spectra recorded at different energies highlight n-type semi-conduction behaviours for both oxides, $\mathrm{Cr}_{2} \mathrm{O}_{3}$ and $\mathrm{Ni}_{1-x} \mathrm{Fe}_{x} \mathrm{Cr}_{2} \mathrm{O}_{4}$.

Moreover, MPEC images recorded at different energies exhibit contrasted regions in photocurrent, describing the distribution of nickel hydroxide and/or nickel ferrite and $\mathrm{Cr}_{2} \mathrm{O}_{3}$ in the oxide film at a micron scale.

It is concluded that PEC techniques represent a sensitive and powerful way to locally analyse the various semiconductor phases in the oxide scale.
\end{abstract}

Keywords:

Oxide film; Nickel base alloys; Photoelectrochemistry; Semiconducting properties; PWR primary medium

\section{Introduction}

The steam generators used in pressurised water reactor (PWR) are made of Ni-base alloys such as alloy 690 or alloy 600. These alloys are oxidized by the primary medium (high temperature hydrogenated aqueous water) of the PWR. During the corrosion process, a passive layer is formed, whose structure and properties play a key role on degradation phenomena such as nickel release in the water, which has for consequence an increase of the contamination, or such as stress corrosion cracking initiation and growth. Different papers describe the oxide film growing on nickel base alloys in PWR simulated primary water as a

*Auteur à qui la correspondance devait être adressée : steph.perrin@cea.fr 
duplex structure [1], [2], [3], [4], [5], [6], [7], [8], [9], [10], [11] and [12]. The internal layer corresponds to an oxide rich in chromium whereas the outer one, which is assumed to be formed by precipitation process [3] and [6], is rich in iron or nickel. Recently, a characterisation by transmission electron microscopy of the oxide layer formed on alloys 690 and $\mathrm{Ni}-30 \mathrm{Cr}$ exposed to PWR primary simulated medium has identified two different oxides composing the internal part [13] and [14]. The major oxide is a continuous film of iron and nickel mixed chromite. At the interface between the alloy and the chromite, nodules of chromia are also present. The outer layer is also composed of two different phases: nickel ferrite crystallites and nickel hydroxide. Nevertheless, if the characterisation by TEM is a powerful way to clearly determine the nature of the different oxide phases constituting the multilayer structure, this technique only consists in a very local analysis. As a consequence, TEM analysis has to be completed by more "global" methods, in order to confirm their representativeness. In this aim, photoelectrochemical experiments were used in order to study the nature of oxide formed, via the determination of their band gap energies, on a larger area of the samples (roughly $0.8 \mathrm{~cm}^{2}$ ) by macro-photoelectrochemistry (PEC) and the surface distribution of these oxides, at the micrometric scale by micro-photoelectrochemistry (MPEC).

PEC experiments were also used in order to study the semiconducting properties of the different oxides, by recording the evolution of photocurrent intensity in function of potential for a given incident light energy. This type of results was then discussed, in one hand, in terms of nature of point defects in oxide and, on the other hand, in terms of microstructural defects [15].

\section{Experimental}

\section{II.1. Materials}

Three alloys were used in this work. The alloys 600 and 690 are the two typical Ni-base alloys used for the manufacturing of steam generators tubes. The third one is a "model" alloy called $\mathrm{Ni}-3 \mathrm{OCr}$ whose chromium content is close to the composition of alloy 690 but Ni-30Cr was quasi iron free. The compositions of the alloys are given in Table 1. Most of the characterisation experiments were performed on alloy 690. Coupons $(30 \mathrm{~mm} \times 20 \mathrm{~mm} \times 2.5 \mathrm{~mm})$ were mechanically mirror-polished with $\mathrm{SiC}$ paper up to grade 1200, diamond paste up to $1 \mu \mathrm{m}$ and alumina gel finish (OPA). Then samples were cleaned first time in distilled water and second time in ethanol-acetone binary mixture in ultrasonic bath.

Table 1: Compositions (wt.\%) of alloys 600,690 and $\mathrm{Ni}-30 \mathrm{Cr}$ studied in this work.

\begin{tabular}{|c|c|c|c|c|c|c|c|c|c|c|c|c|}
\hline \multirow{2}{*}{ Alloys } & \multicolumn{12}{|c|}{ Contents of different alloying elements/wt.\% } \\
\hline & Ni & $\mathbf{C r}$ & $\mathbf{F e}$ & $\mathbf{C}$ & Co & Mn & Al & Ti & $\mathbf{C u}$ & Si & $\mathbf{S}$ & $\mathbf{P}$ \\
\hline 600 & 72.80 & 15.80 & 9.60 & 0.06 & 0.01 & 0.82 & - & 0.20 & 0.01 & 0.31 & $<0.001$ & 0.008 \\
\hline 690 & $59 \cdot 31$ & 29.20 & 9.94 & 0.018 & 0.014 & 0.31 & 0.13 & 0.27 & $<0.002$ & 0.27 & $<0.0005$ & 0.007 \\
\hline Ni-30Cr & 69.15 & 30.35 & 0.25 & 0.002 & - & 0.02 & 0.06 & 0.04 & - & 0.1 & 0.0009 & - \\
\hline
\end{tabular}

\section{II.2. Corrosion tests}

All corrosion tests were performed at $325{ }^{\circ} \mathrm{C}$, under 155 bar in a recirculation autoclave, for test durations from $48 \mathrm{~h}$ up to $858 \mathrm{~h}$. In this testing device, the pressurised hot water was continuously cleaned and purified with ionic exchange resins in the aim of maintaining its concentrations in metallic cations at a low level.

The aqueous solution contained $2 \mathrm{mg} \mathrm{L}^{-1}$ of lithium and $1000 \mathrm{mg} \mathrm{L}^{-1}$ of boron. A hydrogen overpressure of 0.29 bar was maintained to ensure a dissolved $\mathrm{H}_{2}$ concentration of $1.3 \times 10^{-3} \mathrm{~mol} \mathrm{~L}^{-1}$ and a low oxygen content $\left(\mathrm{O}_{2}<10 \mathrm{ppb}\right)$. In these experimental conditions, the calculated $\mathrm{pH}$ of the solution was 7.2 at $325{ }^{\circ} \mathrm{C}$. The corrosion loop used in this work has already been detailed in Ref. [13].

\section{II.3. High temperature oxidation}

$\mathrm{A} \mathrm{Ni}-30 \mathrm{Cr}$ coupon has been oxidized at $900{ }^{\circ} \mathrm{C}$ in 1 bar air during $3 \mathrm{~h}$. The oxide scale formed was roughly $200 \mathrm{~nm}$ thick (SEM observation). 


\section{II.4. High temperature oxidation}

\section{II.4.1. X-ray diffraction under grazing incidence (GIXRD)}

$\mathrm{Ni}-30 \mathrm{Cr}$ coupon oxidized $3 \mathrm{~h}$ at $900{ }^{\circ} \mathrm{C}$ in 1 bar air was analysed by XRD under grazing incidence of $1^{\circ}$ (Panalytical X'Pert MPD with Co anticathode) to determine the crystallographic nature of the oxide films formed on the sample during the oxidation process. XRD analyses were also attempted on nickel base alloys corroded in simulated PWR primary conditions but the obtained results were not convincing, which is probably due to thinness of oxide film (from few $\mathrm{nm}$ to about $10 \mathrm{~nm}$ thick according to different authors [4], [6], [12], [13], [14] and [16]).

\section{II.4.2. Macro-photoelectrochemical technique (PEC)}

The specific device used in this work was developed at the University of Grenoble (France) [17], [18] and [19]. PEC characterisations were performed on oxide scales after corrosion or oxidation tests and cooling down of the sample. The photocurrent was generated by focusing a monochromatic modulated $(\mathrm{f}=21 \mathrm{~Hz})$ beam onto the surface of samples (total area: $0.785 \mathrm{~cm} 2$ ). The monochromatic light was obtained using a xenon lamp (LAX 1000, Muller Gmbh, emission spectrum: $\lambda>200 \mathrm{~nm}$ ), associated to a monochromator (PAR 1235 EG\&G). The light modulation was achieved by the means of mechanical chopper (PAR 197, EG\&G). The oxidized or corroded sample was used as the working electrode in a classical three electrodes electrochemical cell. The electrolyte was a deaerated sodium sulphate aqueous solution $(0.5 \mathrm{~mol} \mathrm{~L}-1)$ containing sodium hydroxide adjunction $(\mathrm{pH}=8)$ and the reference electrode was a KCl-saturated calomel electrode $(\mathrm{SCE},+0.245 \mathrm{~V} / \mathrm{NHE})$ or a mercury sulphate electrode (MSE, +0.650 V/NHE). A platinum foil was used as counter-electrode. The lock-in technique was applied to separate the photocurrent from the total current of the cell.

For this, the current output of the potentiostat (IMT101/DEA332, Radiometer Analytical Chemistry) was connected to the signal input of the lock-in amplifier (PAR 5208, EG\&G) and the trigger signal of the light modulator was fed to the reference input of the lock-in amplifier. The raw photocurrent was recorded by a home-made software as a function of photon energy for an applied potential or as a function of potential for an incident wavelength.

When the photocurrent was recorded as a function of photon energy, the wavelengths investigated in this work varied in the range of $220-562 \mathrm{~nm}$. In order to prevent any harmonic contribution to the illumination, the PEC spectra were recorded in two parts. The first part of the spectra was recorded in the 220-440 $\mathrm{nm}$ range, where the harmonics of the fundamental wavelengths (in the 110-220 nm range or lower) cannot produce any significant contribution on the PEC spectra. On the contrary, for the second part of the spectra, in the $440-562 \mathrm{~nm}$ range, the harmonics of the fundamental wavelengths (in the $220-281 \mathrm{~nm}$ range or lower) can produce significant outputs on the recorded PEC spectra. In order to prevent any contributions due to these harmonics, a low-pass filter in frequency (centred at $380 \mathrm{~nm}$ ) which totally cut the wavelengths below $350 \mathrm{~nm}$, has been used when the PEC spectra were recorded in the specific $440-562 \mathrm{~nm}$ range.

In order to interpret correctly the PEC spectra recorded, particularly in the case of band gaps determination, the most important physical quantity to take into consideration is the quantum yield, and not the as-measured photocurrent values, which deeply depend on the photon flux produced by the experimental device at each wavelength.

The photon flux in function of the wavelength was obtained by means of a calibrated photodiode (Hamamatsu Photonics S1722-02) positioned in the same place of the sample. Nevertheless, in the experimental device that was used, the illuminated areas of the sample and the photodiode are not well known because a polymer seal was used to ensure the tightness between the sample or the photodiode and the sample-holder. Due to the lack of precision on the measure of the true illuminated area, in order to avoid important errors that could be made on the determination of the absolute photon flux, and then on the absolute external quantum yield, the authors have chosen to normalize the measured incident flux with the value obtained at its maximum.

To obtain photocurrent values proportional to the quantum yield, the as-measured values of the photocurrent were divided, at each wavelength, by the corresponding normalized photon 
flux at the electrode surface. This "corrected photocurrent" is designated in the following by Iph and simply called photocurrent.

\section{II.4.3. Micro-photoelectrochemical technique (MPEC)}

The MPEC device used in this work was described elsewhere [15] and [20]. The photocurrent is generated using the modulated $(f=21 \mathrm{~Hz})$ monochromatic light from an Argon laser (Innova 90C-A6, Coherent, $\lambda=351 \mathrm{~nm}$ or $\lambda=454 \mathrm{~nm}$ ). The beam is focused onto the surface of the oxidized or corroded sample studied via UV-light-objective or visible-light-objective of an inverted microscope (spot size $\sim 1 \mu \mathrm{m}$ for visible-light-objective or spot size $\sim 0.5 \mu \mathrm{m}$ for UV-light-objective). The image is built by moving a high resolution XY motorized XY stage (Marzhauser, Scan IM120 $\times 100$ ) ensured with a positioning system (two axes stepping motor controller: LStep, Lang Gmbh). The sample is used as the working electrode in a classical three-electrodes electrochemical cell with a flat quartz bottom. The reference electrode is the mercury sulphate electrode (MSE, +0.650 V/NHE); the counter-electrode is a platinum plate of $1 \mathrm{~cm}^{2}$ area. The electrolyte is deaerated sodium sulphate aqueous solution $\left(0.5 \mathrm{~mol} \mathrm{~L}^{-1}\right)$ containing sodium hydroxide adjunction $(\mathrm{pH}=8)$.

The lock-in technique is applied to separate the photocurrent from the total electrochemical current. For that purpose, the current output of the potentiostat (PAR 273A, EG\&G) is connected to the signal input of the lock-in amplifier (Stanford Research SR830) and the trigger signal of the optic light modulator (PAR 197, EG\&G) is fed to the reference input of the lock-in amplifier. A photoelectrochemical image is built at a given applied potential, by recording for each position of the stage, the intensity amplitude of the photocurrent. The investigated area is selected within the optical image provided by a CCD camera. The whole instrumentation is controlled by a home-made software.

In the MPEC images performed in this work, the power applied to the analysed surface was $~$ $1.4 \mathrm{~mW}$ at $\lambda=351 \mathrm{~nm}$ and $\sim 0.4 \mathrm{~mW}$ at $\lambda=454 \mathrm{~nm}$. At this level of power, thermal effects cannot be excluded. Nevertheless, two experimental points for which the effect of these powers could affect the recorded photocurrents have been checked. Firstly, it has been verified, for an applied potential, that the evolution of photocurrent in function of power is linear. Then, it has been checked that, for an applied potential, the evolution of photocurrent in time (few minutes) on a same area, is reproducible. Even if these two last experimental observations cannot permit to totally exclude thermal effects, these observations seem to show that thermal effects are not the main cause of photocurrent fluctuations observed on MPEC images.

Table 2 summarizes the different corrosion tests and oxide film characterisations which have been realized.

Table 2: Corrosion tests and oxide film characterisations performed in this work.

\begin{tabular}{llll}
\hline $\begin{array}{l}\text { Test } \\
\text { durations/h }\end{array}$ & Experimental conditions & Alloys & Oxide film characterisations \\
\hline 3 & $900^{\circ} \mathrm{C}$ in 1 bar air & $\mathrm{Ni}-30 \mathrm{Cr}$ & $\mathrm{GIXRD}, \mathrm{PEC}$ \\
48 & $325^{\circ} \mathrm{C}$ and 155 bar in PWR primary simulated & 690 & $\mathrm{PEC}, \mathrm{MPEC}$ \\
66 & media conditions & 690 & $\mathrm{PEC}$ \\
112 & & 690 & $\mathrm{PEC}$ \\
164 & & 690 & $\mathrm{PEC}$ \\
406 & & 690 & $\mathrm{PEC}, \mathrm{MPEC}$ \\
858 & 600 & PEC \\
& & 690 & PEC, MPEC \\
\hline
\end{tabular}

\section{Results}

\section{III.1. Nature of the oxide scales}

\section{III.1.1. Preliminary data about band gaps of nickel, chromium and iron oxides}

The band gap values of nickel, chromium and iron oxides, which have been observed [1], [2], [3], [4], [5], [6], [7], [8], [9], [10], [11], [12], [13] and [14] or could be expected to form during the corrosion process of nickel base alloys under the simulated PWR primary conditions, have 
been collected on the basis of a literature research [19], [21], [22], [23], [24], [25], [26], [27], [28], [29], [30], [31], [32], [33], [34], [35] and [36].

The band gap of magnetite $\left(\mathrm{Fe}_{3} \mathrm{O}_{4}\right)$ was roughly $0.2 \mathrm{eV}$ [21], corresponding to an energy range which is not investigated in this work.

For hematite $\left(\alpha-\mathrm{Fe}_{3} \mathrm{O}_{4}\right)$, an indirect transition was reported by several authors, ranging between $1.9 \mathrm{eV}$ and $2.2 \mathrm{eV}$ [19], [22], [23] and [24]. This oxide was typically an n-type semiconductor.

A semi-empirical correlation between the optical band gap of oxides and hydroxides and the electronegativity of their constituents has been developed by Di Quarto et al. [25] and [26]. The band gap value of nickel hydroxide was calculated, using this correlation, by Di Quarto et al. [26], and the obtained value was $2.25 \mathrm{eV}$. This last value is in good agreement with the value estimated by Di Quarto et al. [26] (2.3 eV), by assuming indirect optical transition from the photocurrent spectrum reported by Carpenter et al. [27], for $\beta-\mathrm{Ni}(\mathrm{OH})_{2}$ deposited cathodically.

The band gap of $\mathrm{Cr}(\mathrm{OH})_{3}$ has been measured, assuming indirect optical transition, at roughly $2.4 \mathrm{eV}$, by several authors [26] and [28].

The band gap of the rhombohedric infinite solid solution $(\mathrm{Fe}, \mathrm{Cr})_{2} \mathrm{O}_{3}$, seldom studied, was reported as an indirect transition at $2.65 \mathrm{eV}$ [19].

The value of $\sim 3.5 \mathrm{eV}$ is generally reported in the literature for bulk $\mathrm{Cr}_{2} \mathrm{O}_{3}$ [28], [29] and [30]. This oxide can behave as insulator, n-type or p-type semiconductor [30]. In a more recent study, published by Henry et al. [31], a second contribution at $\sim 2.9 \mathrm{eV}$ was attributed to $\mathrm{Cr}_{2} \mathrm{O}_{3}$ located in the inner part of the oxide scale [31], possibly due to the inward growing direction of this subscale.

The nickel oxide $\mathrm{NiO}$ was a p-type semiconductor with a band gap included in the range 3.5$3.9 \mathrm{eV}$ [23], [32], [33] and [34]. This band gap was calculated assuming an indirect transition on the one hand [23], and a direct transition on the other hand [32], [33] and [34].

Two very different band gap values, based on optical measurements, have been found in the literature for $\mathrm{NiFe}_{2} \mathrm{O}_{4}$. Balaji et al. [35] reported a value of $\sim 2.2 \mathrm{eV}$, but Srivastava et al. [36] reported a value of $\sim 5 \mathrm{eV}$, assuming a direct transition.

For $\mathrm{NiCr}_{2} \mathrm{O}_{4}$ and $\mathrm{FeCr}_{2} \mathrm{O}_{4}$, no band gap values were found in the literature.

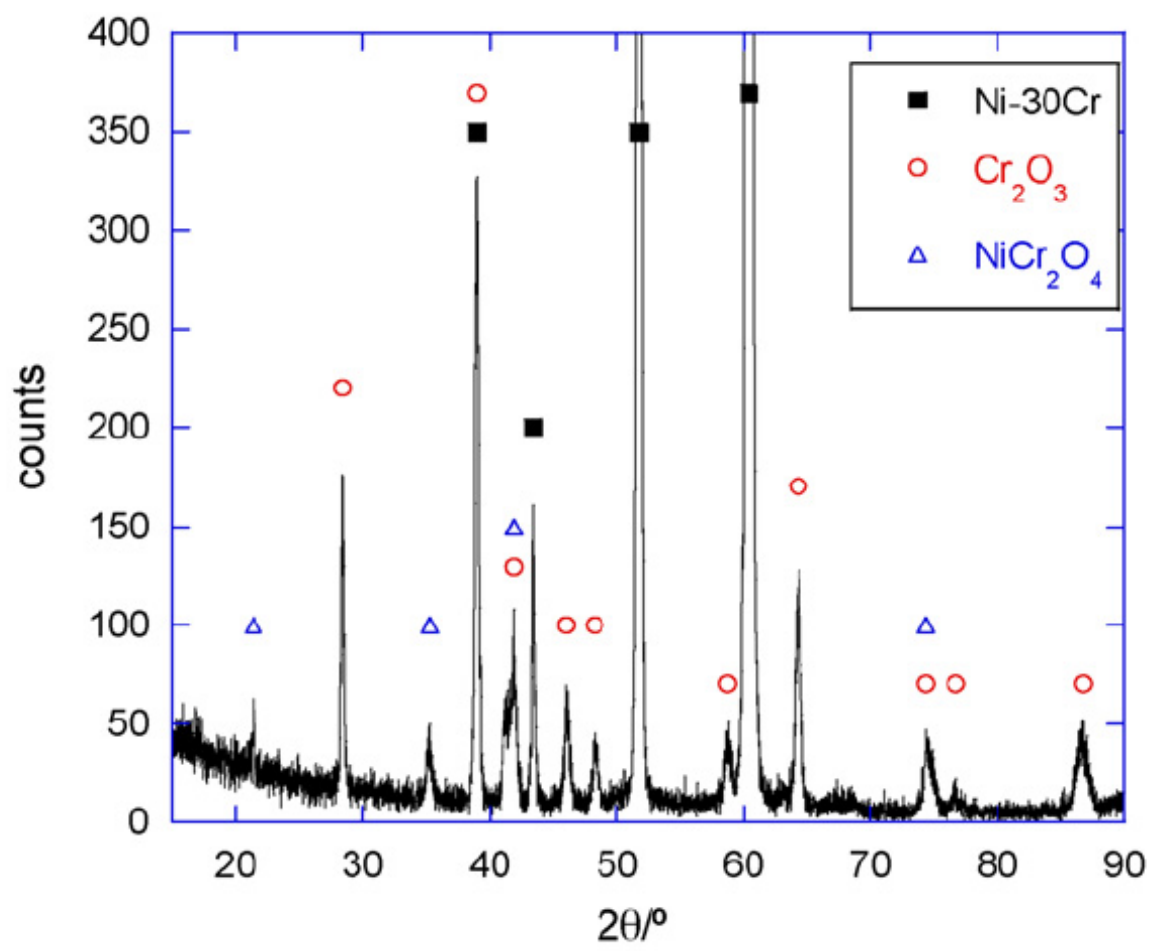

Figure 1: Diffractogram obtained by GIXDR under $1^{\circ}$ on $\mathrm{Ni}-3 \mathrm{OCr}$ coupon oxidized $3 \mathrm{~h}$ at $900{ }^{\circ} \mathrm{C}$ in 1 bar air, which underlined that oxide scale was composed of $\mathrm{Cr}_{2} \mathrm{O}_{3}$ and $\mathrm{NiCr}_{2} \mathrm{O}_{4}$ 
III.1.2. Photoelectrochemical study of $\mathrm{Ni}-3 \mathrm{OCr}$ alloy oxidized at $900{ }^{\circ} \mathrm{C}$

The $\mathrm{Ni}-30 \mathrm{Cr}$ coupon oxidized at $900{ }^{\circ} \mathrm{C}$ in 1 bar air during $3 \mathrm{~h}$ has been analysed by XRD under grazing incidence $\left(1^{\circ}\right)$. The diffraction diagram obtained is presented in Figure 1. Diffraction peaks observed fitted well to an oxide film is made of $\mathrm{Cr}_{2} \mathrm{O}_{3}$ (JCPDS file \#38-1479) and $\mathrm{NiCr}_{2} \mathrm{O}_{4}$ (JCPDS file \#23-0432).

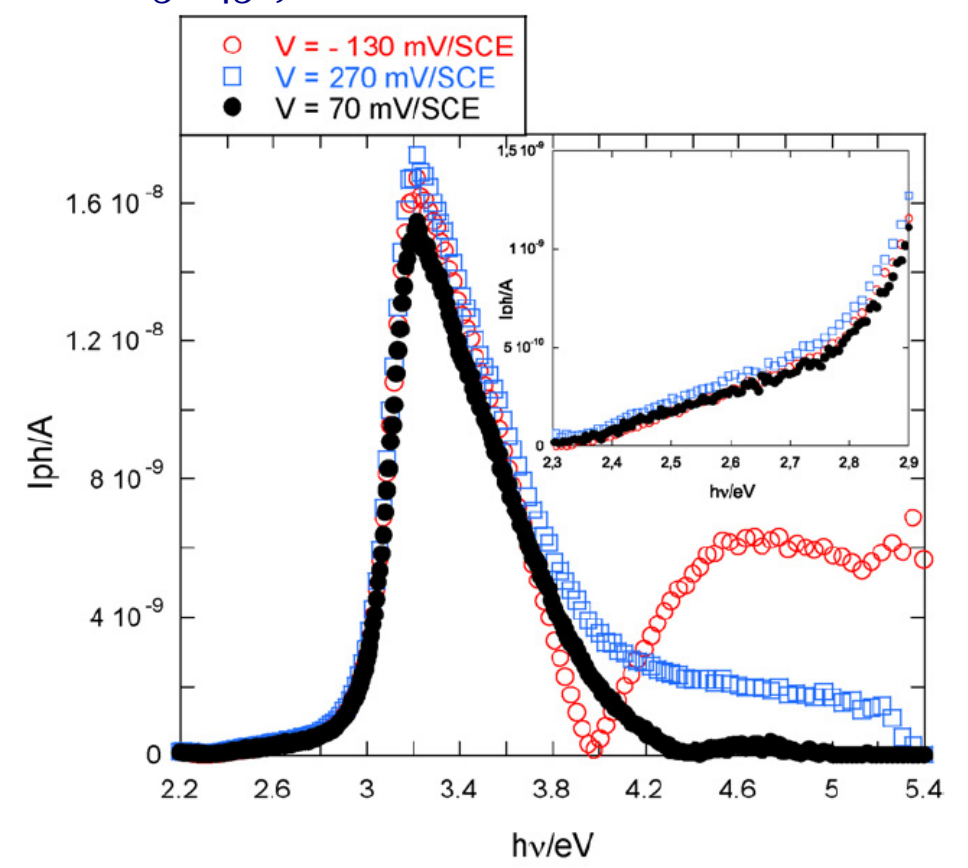

Figure 2: Photocurrent vs. light energy spectra obtained on $\mathrm{Ni}-3 \mathrm{OCr}$ coupon oxidized $3 \mathrm{~h}$ at $900{ }^{\circ} \mathrm{C}$ in 1 bar air for 3 different potentials; inset: zoom in the 2.3-2.9 $\mathrm{eV}$ range.

Three PEC spectra, photocurrent intensity function of light energy, were recorded on this sample (Figure 2): one at the open circuit potential (Voc=70 $\mathrm{mV} / \mathrm{SCE}$ ), one for an anodic polarization $(\mathrm{V}=270 \mathrm{mV} / \mathrm{SCE})$ and one for a cathodic polarization $(\mathrm{V}=-130 \mathrm{mV} / \mathrm{SCE})$. These spectra revealed two major photocurrent contributions.

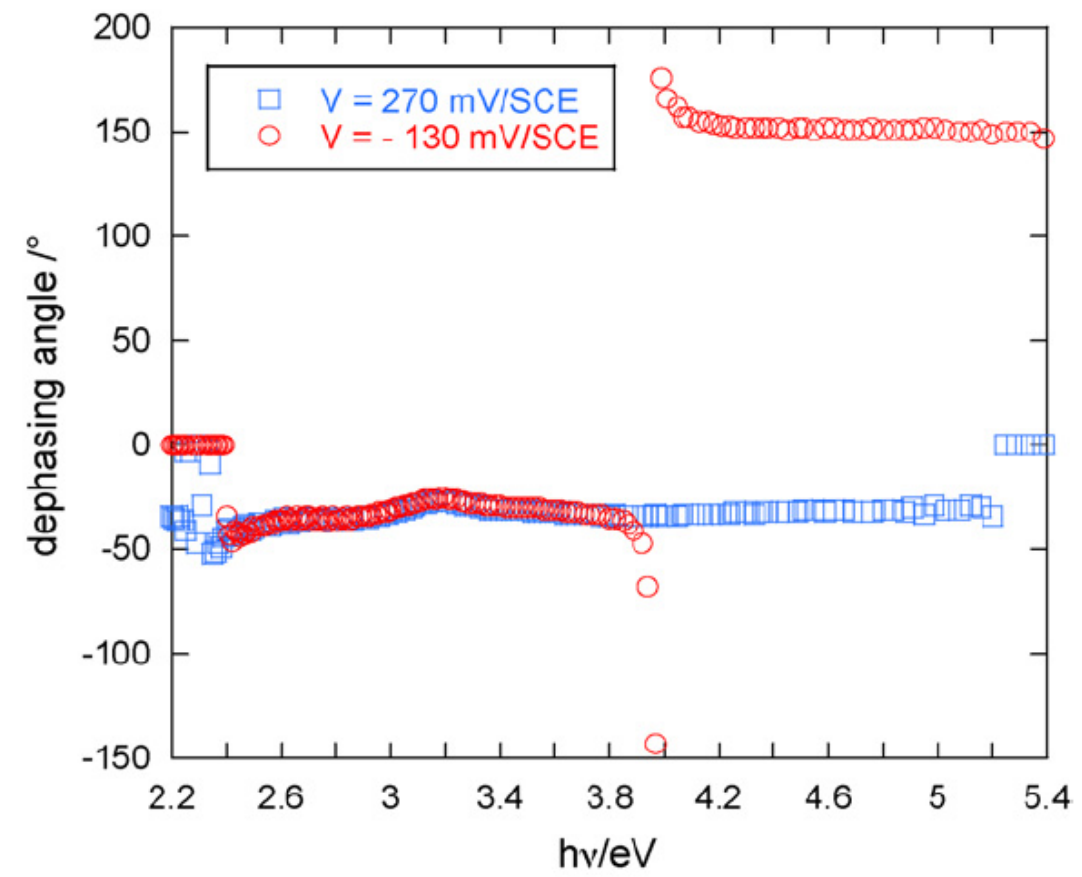

Figure 3: Evolution of the dephasing angle of the photocurrent vs. light energy obtained on $\mathrm{Ni}-30 \mathrm{Cr}$ coupon oxidized $3 \mathrm{~h}$ at $900{ }^{\circ} \mathrm{C}$ in 1 bar air for anodic and cathodic polarizations. 
The more intensive contribution peaked at about $3.3 \mathrm{eV}$ whatever the applied potential. The second contribution was low at open circuit potential and more intense for anodic and cathodic polarization. The higher photocurrent was obtained for cathodic polarization and peaking at about $4.6 \mathrm{eV}$. For this polarization, the photocurrent was null at about $4 \mathrm{eV}$ corresponding to a reversal of the dephasing angle of the photocurrent (Figure 3) which was not observed for anodic polarization. It must be pointed out that in this work, the reference phase was not set to zero by the use of a calibrated photodiode. Nevertheless, if the values of the phase shift cannot be interpreted in an absolute way, the relatively great change in the phase shift $\left(\sim 180^{\circ}\right)$ observed in Figure 3 suggests that the first contribution can be attributed to an n-type semiconductor whereas the second contribution exhibits the typical behaviour of an insulator (successively n-type and p-type semiconducting properties depending of the polarization).
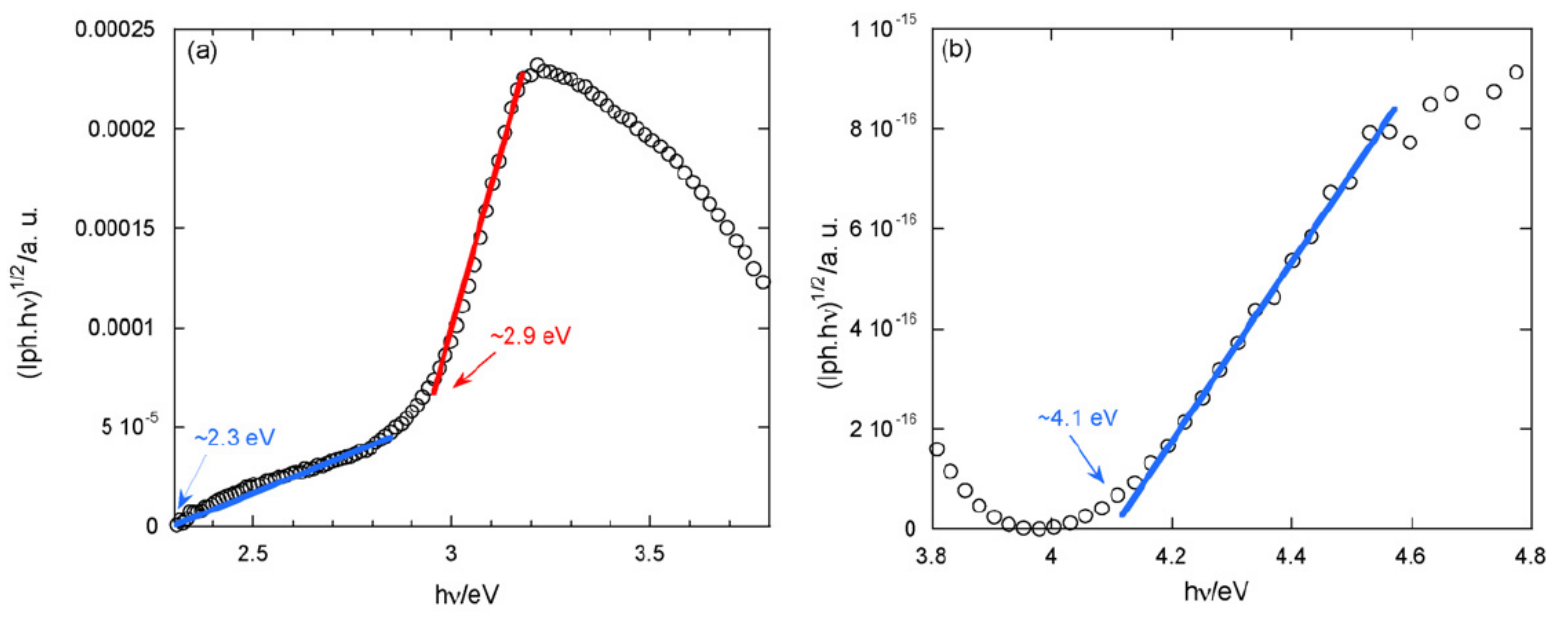

Figure 4: (a) $(\text { Iph } \times h v)^{1 / 2} v s$. hv and (b) $(\text { Iph } \times h v)^{2} v s$. hv transforms applied to the curve Iph vs. hv obtained for cathodic polarization (Figure 2) showing the band gaps of the different phases contributing to the photocurrent.

It can already be pointed out that another minor contribution, revealing a low but significant photocurrent, seems to be observed in Figure 2 (see inset), in the 2.3-2.9 eV energy range.

The mathematical transforms $(\mathrm{Iph} \times \mathrm{hv})^{1 / 2} \mathrm{vs.} \mathrm{hv}$ and $(\mathrm{Iph} \times \mathrm{hv})^{2} \mathrm{vs}$. hv, derived from direct and indirect optical transitions [23], [37] and [38], applied to the curve obtained for cathodic polarization could lead to the determination of the band gaps values (Figure 4a and b) of the different phases contributing to the photocurrent. As it has been discussed in Section III.1.1, Henry et al. [31] have attributed the indirect band gap value at $\sim 2.9 \mathrm{eV}$ to $\mathrm{Cr}_{2} \mathrm{O}_{3}$ located in the inner part of the oxide scale, possibly due to the inward growing direction of this subscale. Moreover, Calvarin et al. [39] have studied the oxidation mechanism of $\mathrm{Ni}-20 \mathrm{Cr}$ at $900{ }^{\circ} \mathrm{C}$ in air and reported such an inward growth of the $\mathrm{Cr}_{2} \mathrm{O}_{3}$ subscale. According to the literature data [31] and [39] and diffraction diagram presented in Figure 1, it is proposed to attribute the indirect transition observed at $\sim 2.9 \mathrm{eV}$, corresponding to the more intensive contribution (see Figure 2), to $\mathrm{Cr}_{2} \mathrm{O}_{3}$, taking into account that this subscale probably grows inward on $\mathrm{Ni}-3 \mathrm{OCr}$ oxidized at $900{ }^{\circ} \mathrm{C}$ in air. In the same way, the second contribution observed in Figure 2, corresponded to the direct transition observed at $\sim 4.1 \mathrm{eV}$, and not mentioned in the literature was attributed to $\mathrm{NiCr}_{2} \mathrm{O}_{4}$.

The evolution of the photocurrent in function of the potential for a light energy equal to $4.4 \mathrm{eV}$ is presented (Figure 5). It points out that this oxide presents mixed semiconducting properties with both p-type and n-type contributions according to the evolution of the dephasing angle of the photocurrent presented in Figure 3.

It can be underlined that a minor indirect contribution was observed at $\sim 2.3 \mathrm{eV}$ in Figure 4 . A band gap of $\sim 2.3 \mathrm{eV}$ could correspond to a thin film of either $\mathrm{Ni}(\mathrm{OH})_{2}, \mathrm{Cr}(\mathrm{OH})_{3}$, or a mixed $\mathrm{Ni}-\mathrm{Cr}$ hydroxide [26], [27] and [28], probably formed during the immersion of the sample in the basic electrolyte used for photoelectrochemical measurements. 


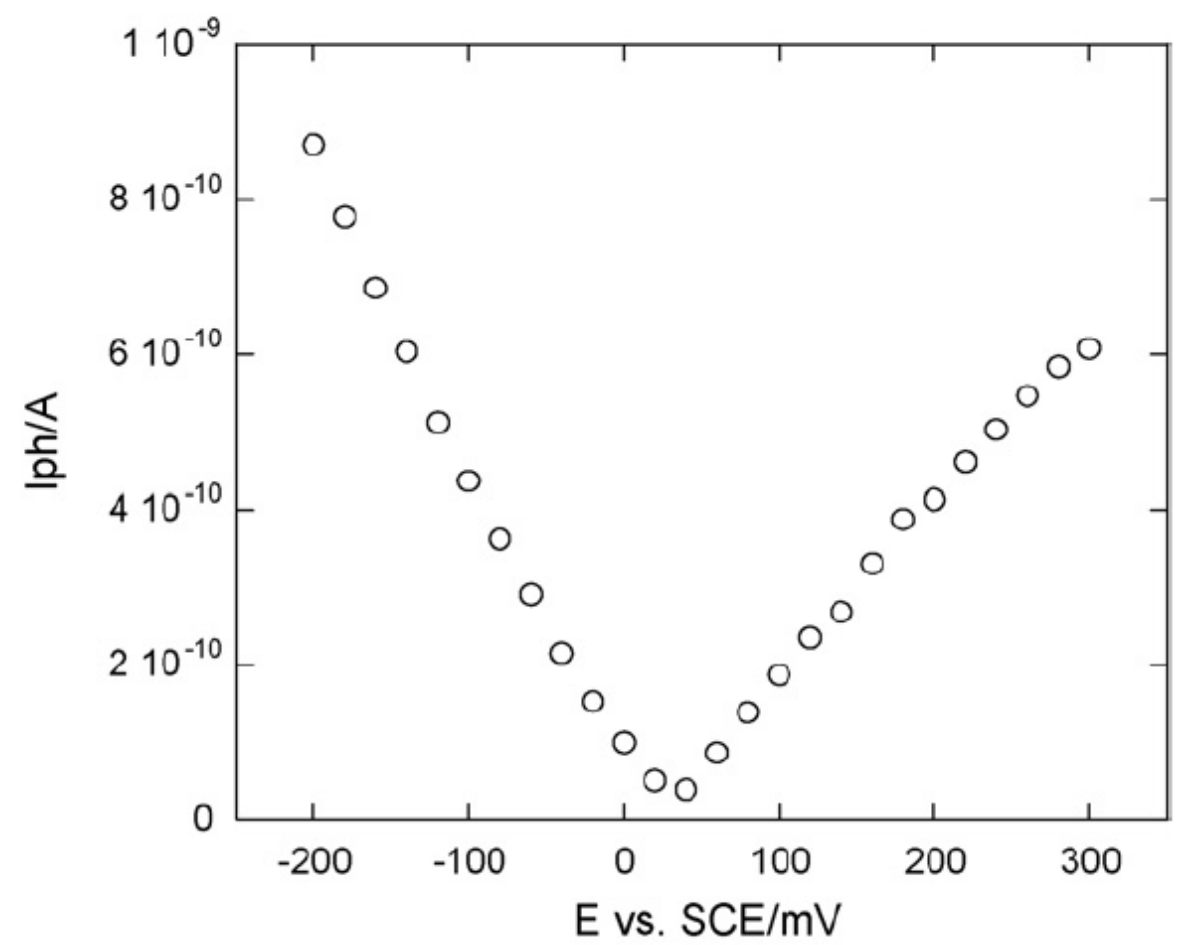

Figure 5: Photocurrent vs. potential obtained on $\mathrm{Ni}-30 \mathrm{Cr}$ coupon oxidized $3 \mathrm{~h}$ at $900{ }^{\circ} \mathrm{C}$ in 1 bar air for a light energy equal to $4.4 \mathrm{eV}$.

III.1.3. Photoelectrochemical study of alloy 690 corroded $858 \mathrm{~h}$ in simulated PWR primary conditions

The PEC spectrum recorded on the alloy 690 corroded $858 \mathrm{~h}$ in simulated PWR primary conditions is presented in Figure 6 for different polarization potentials. No significant photocurrent emerges from the background noise when the sample is polarized at cathodic potential $(-300 \mathrm{mV} / \mathrm{SCE})$. On the contrary, for an anodic polarization $(450 \mathrm{mV} / \mathrm{SCE})$, a photocurrent appears on the sample.

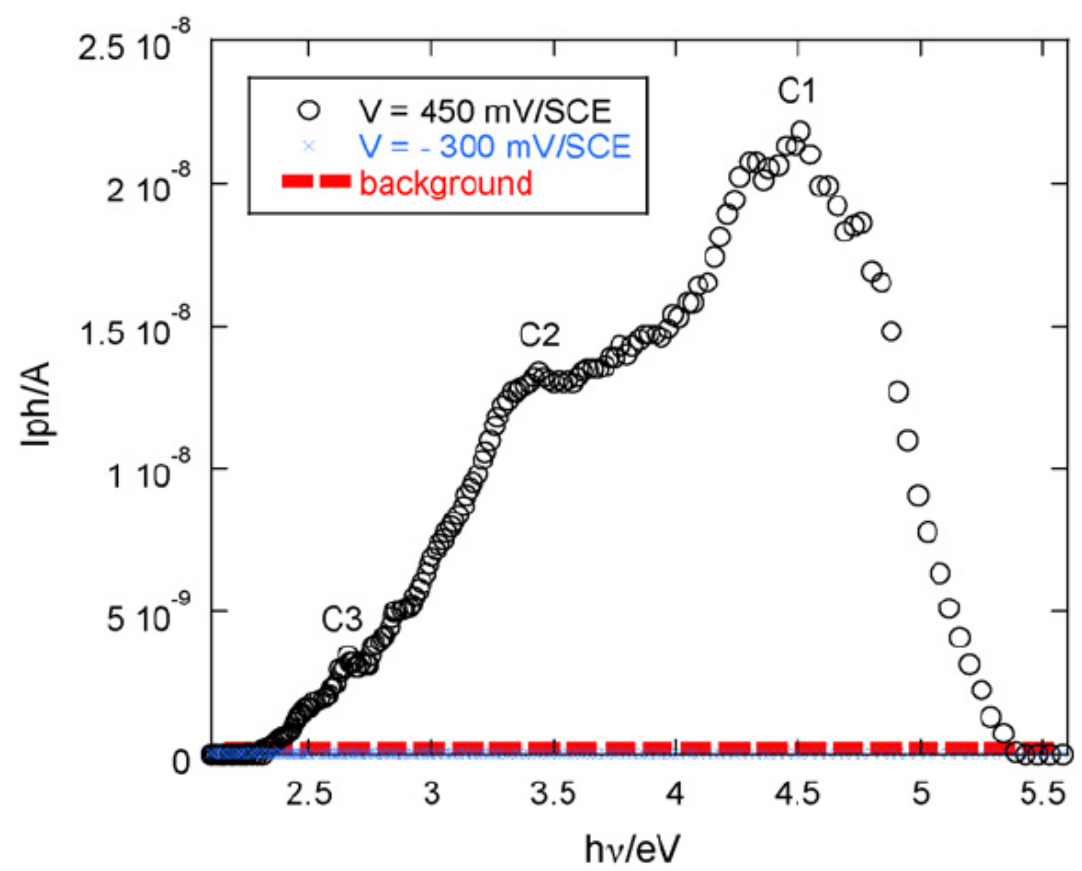

Figure 6: Photocurrent vs. light energy spectra obtained on the alloy 690 coupon corroded $858 \mathrm{~h}$ in simulated $P W R$ primary conditions for 2 different potentials. 
This result is coherent with the presence of n-type semiconductor oxides in the oxide layer. Three contributions appear for an anodic polarization. The top of the main principal contribution (called $\mathrm{C} 1$ in Figure 6 and in the following) is observed for an energy of approximately $4.4 \mathrm{eV}$. A second contribution (called $\mathrm{C} 2$ ), whose maximum intensity appears for an energy of about $3.5 \mathrm{eV}$, is also highlighted. Lastly, a weaker photocurrent (this contribution was called $\mathrm{C}_{3}$ ) is recorded in the energy range of $\sim 2.2 \mathrm{eV}$ to $\sim 2.7 \mathrm{eV}$.
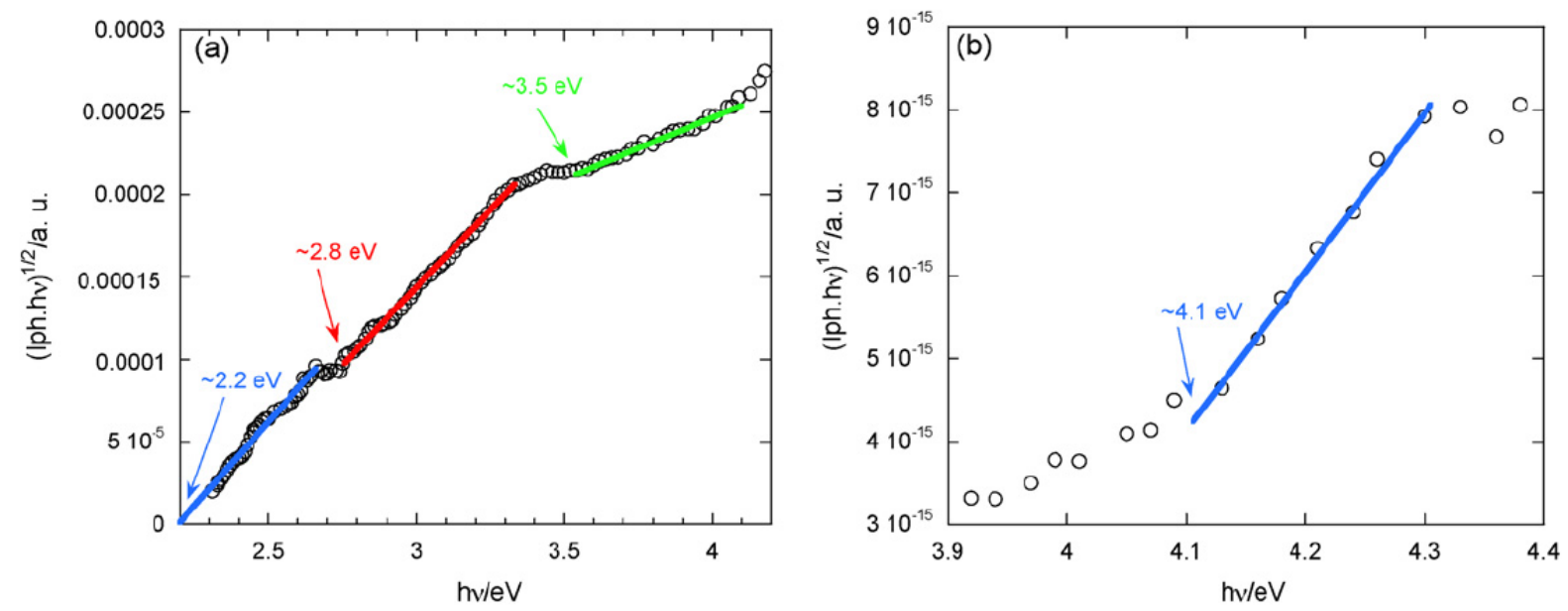

Figure 7: (a) $(I p h \times h v)^{1 / 2} v s . h v$ and $(b)(I p h \times h v)^{2} v s$. hv transforms applied to the curve Iph vs. hv obtained for anodic polarization (Figure 6) for alloy 690 corroded $858 \mathrm{~h}$ in simulated PWR primary conditions.

The $(\mathrm{Iph} \times \mathrm{hv})^{1 / 2}$ vs. hv and $(\mathrm{Iph} \times \mathrm{h} v)^{2}$ vs. hv transforms applied to the curves obtained under anodic polarization are drawn in Figure $7 \mathrm{a}$ and b. Four band gaps determinations were proposed. One indirect transition, which corresponds to the band gap value of $\sim 2.2 \mathrm{eV}$, could be attributed to the presence of nickel hydroxide. Nevertheless, according to some of the literature data concerning the band gap of nickel ferrite [35], the band gap value at $\sim 2.2 \mathrm{eV}$ could be also attributed to the presence of $\mathrm{NiFe}_{2} \mathrm{O}_{4}$. The presence of nickel hydroxide and/or nickel ferrite in the oxide layer formed on nickel base alloys exposed to PWR primary simulated conditions is consistent with the results previously published in the literature [1], [7], [10], [13] and [14]. Fig. 7a also underlines two indirect transitions at energies of $\sim 2.8 \mathrm{eV}$ and $\sim 3.5 \mathrm{eV}$. According to the literature data discussed above (see Section 3.1.1) about the contributions associated to $\mathrm{Cr}_{3} \mathrm{O}_{3}$ [28], [29], [30] and [31], these two transitions can be attributed to the presence of this oxide. This interpretation, exhibiting the presence of chromia, is consistent, on the one hand, with the results reported in Refs. [13] and [14], where $\mathrm{Cr}_{2} \mathrm{O}_{3}$ nodules have been observed along the alloy 690/oxide scale interface by highresolution transmission electron microscopy (HRTEM), and on the other hand, with the study of the growth mechanism of oxide scale formed on Ni-base alloys during their exposition in PWR primary media, which exhibits an inward growing of the protective oxide scale[40].

It can be highlighted that the change of slope between the two contributions started at $\sim 2.2 \mathrm{eV}$ and $\sim 2.8 \mathrm{eV}$ (Figure $7 \mathrm{a}$ ) is weak. This weakness may be due to the sum of two effects: the decrease (at $\sim 2.7 \mathrm{eV}$ ) of the contribution starting at $\sim 2.2 \mathrm{eV}$ and the increase of the contribution starting at $\sim 2.8 \mathrm{eV}$. Finally, Figure $7 \mathrm{~b}$ highlights a direct transition corresponding to a gap of approximately $4.1 \mathrm{eV}$. For the oxide layer formed on alloy 690 , the observations by HRTEM revealed the presence of a continuous layer of mixed iron and nickel chromite [13] and [14]. It was also previously shown, with the oxide formed on alloy $\mathrm{Ni}-\mathrm{Cr}$ at $900^{\circ} \mathrm{C}$ under air, that $\mathrm{NiCr}_{2} \mathrm{O}_{4}$ presents also a direct gap of $4.1 \mathrm{eV}$. The same gap was measured for alloy $\mathrm{Ni}-3 \mathrm{OCr}$ corroded in PWR simulated conditions (these last results are close to the results obtained on alloy 690 and are not shown here). As a consequence the direct transition observed on the oxide formed on nickel base alloy in PWR primary medium can be attributed to a mixed chromite, $\mathrm{Ni}_{1-x} \mathrm{Fe}_{x} \mathrm{Cr}_{2} \mathrm{O}_{4}$. The substitution of nickel by iron in the spinel structure induces therefore only a very weak effect on the band gap value. In this way, it can be pointed out that the main contribution at $4.5 \mathrm{eV}$ (see Figure 6) could be interpreted as 
two close peaks. This two-peaked shape could be due to the substitution of nickel by iron in the mixed chromite formed in primary media.

\section{III.2. Evolution of the oxide scale in function of the exposition time}

In order to identify the different oxides using photoelectrochemical method, this technique was first applied to samples exposed $858 \mathrm{~h}$ in the primary simulated medium because it enables to study a layer which is the thickest achieved. So the maximum of carriers were obtained by PEC and consequently the intensity of the signal was optimized. This part deals with the evolution of the oxide formed at different durations on alloy 690 oxidized between $48 \mathrm{~h}$ and $858 \mathrm{~h}$ in PWR simulated primary water.

Three or four oxides were identified in the previous part: nickel hydroxide and/or nickel ferrite, $\mathrm{Cr}_{2} \mathrm{O}_{3}$ and $\mathrm{Ni}_{1-x} \mathrm{Fe}_{x} \mathrm{Cr}_{2} \mathrm{O}_{4}$. For each one, a maximal photocurrent can be measured corresponding to energy of $\sim 2.8 \mathrm{eV}\left(\mathrm{C}_{3}\right), \sim 3.5 \mathrm{eV}\left(\mathrm{C}_{2}\right)$ and $\sim 4.4 \mathrm{eV}\left(\mathrm{C}_{1}\right)$. Among all the experiments, the highest photocurrent value $\left(\mathrm{Iph}_{\max }\right)$ has been obtained at $4.4 \mathrm{eV}$ on the sample exposed $858 \mathrm{~h}$. In order to follow the evolution of each oxide, for all experiments, the corresponding "peak" photocurrent intensity $\left(\mathrm{C}_{1}, \mathrm{C}_{2}\right.$ and $\left.\mathrm{C}_{3}\right)$ has been normalized by $\mathrm{Iph}_{\max }$. Figure 8 illustrates the evolution of each oxide function of exposure time. The background of the measure has also been evaluated as shown in Figure 8 (dashed line).

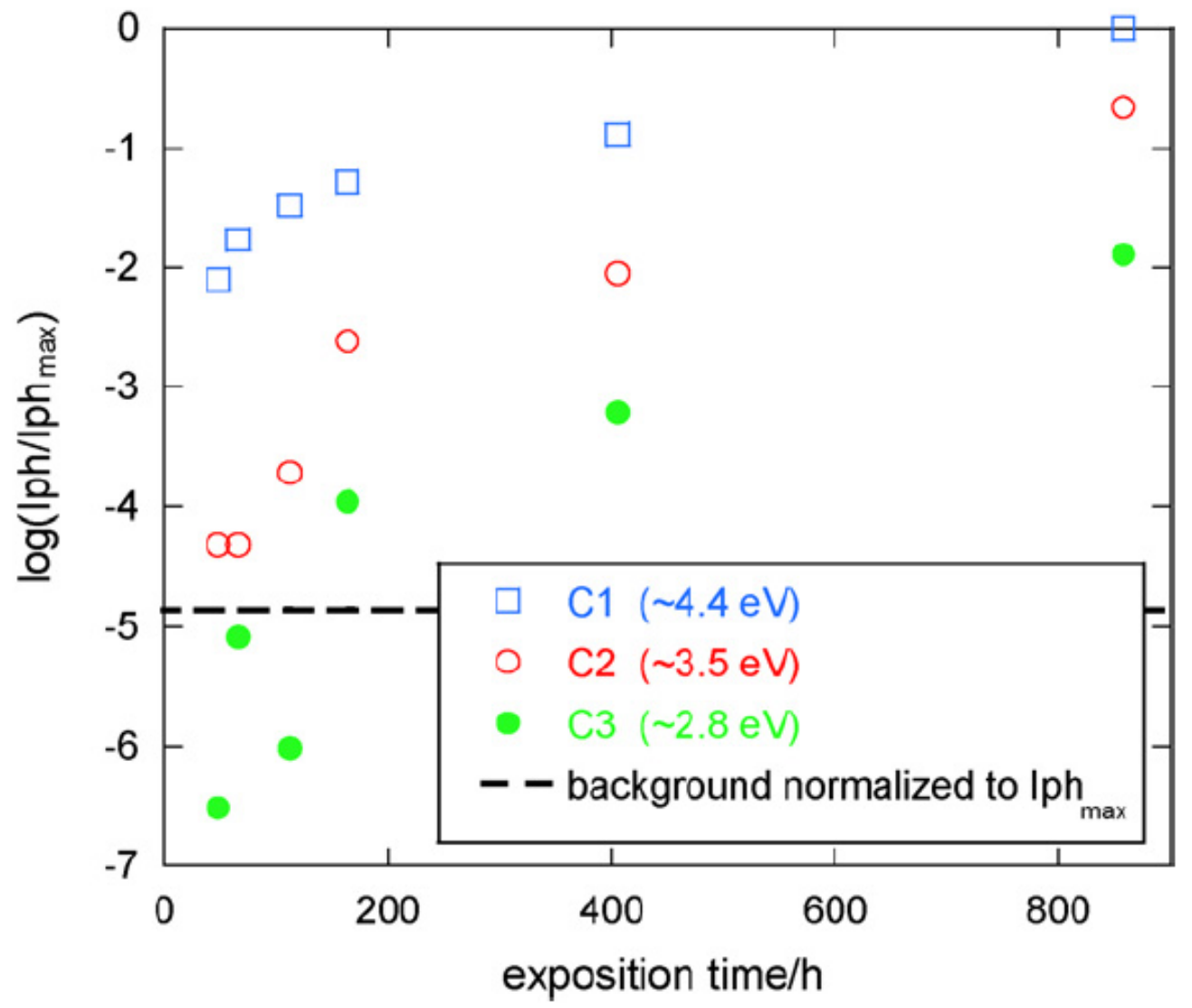

Figure 8: Evolution of the maximal value of the photocurrent for the contributions corresponding to $C_{3}$ $(\sim 2.8 \mathrm{eV}), \mathrm{C} 2(\sim 3.5 \mathrm{eV})$ and $\mathrm{C1}_{1}(\sim 4.4 \mathrm{eV})$ divided by the maximal photocurrent (obtained at $4.4 \mathrm{eV}$ and for the maximal corrosion duration, $858 \mathrm{~h}$ ) function of the exposure time for alloy 690 corroded in PWR primary conditions.

The contributions corresponding to $\mathrm{Cr}_{2} \mathrm{O}_{3}(\mathrm{C} 2)$ and to $\mathrm{Ni}_{1-x} \mathrm{Fe}_{x} \mathrm{Cr}_{2} \mathrm{O}_{4}$ (C1) are significant whatever the corrosion duration. This result underlines that these two oxides are always present in the oxide layer. On the contrary, the contribution at $\sim 2.8 \mathrm{eV}\left(\mathrm{C}_{3}\right)$, linked to the presence of nickel hydroxide and/or nickel ferrite, is significant only after a duration of $164 \mathrm{~h}$. Two reasons can explain this result: these compounds are not formed before this duration or the quantity formed is so weak that the photocurrent intensity is under the detection limit of measure. Nevertheless, Machet et al. [7] and [10] have observed by XPS, the formation of 
nickel hydroxide for very short exposure times (few minutes), which enables to conclude that the hydroxide is probably present for all the corrosion times presented in this paper. Finally, for all the oxides, an increase of the intensity with time is observed, which can be interpreted as an increase of the quantity of the oxide formed in function of the oxidation duration.

\section{III.3. Semiconducting properties of the oxide scale}

In order to study the semiconducting properties of the two main oxides present in the scale, the evolution of the photocurrent has been measured in function of the applied potential for an alloy 690 sample corroded $858 \mathrm{~h}$ in PWR primary simulated medium for two light energies, $\sim 3.5 \mathrm{eV}$ (the contribution $\mathrm{C} 2$ corresponding to $\mathrm{Cr}_{2} \mathrm{O}_{3}$ ) and $\sim 4.4 \mathrm{eV}$ (the contribution $\mathrm{C} 1$ corresponding to $\mathrm{Cr}_{2} \mathrm{O}_{3}$ and $\mathrm{Ni}_{1-x} \mathrm{Fe}_{x} \mathrm{Cr}_{2} \mathrm{O}_{4}$ ). The curves presented in Figure 9 permit to conclude that these two oxides formed in PWR primary conditions are n-semiconductors. This well agrees with the absence of photocurrent when a cathodic polarization is applied to the sample (Figure 6). The n-type semiconducting properties of the oxide layer has already been observed by Szklarska-Smialowska et al. [41] for alloy 600 corroded in an aqueous hydrogenated medium at high temperature.

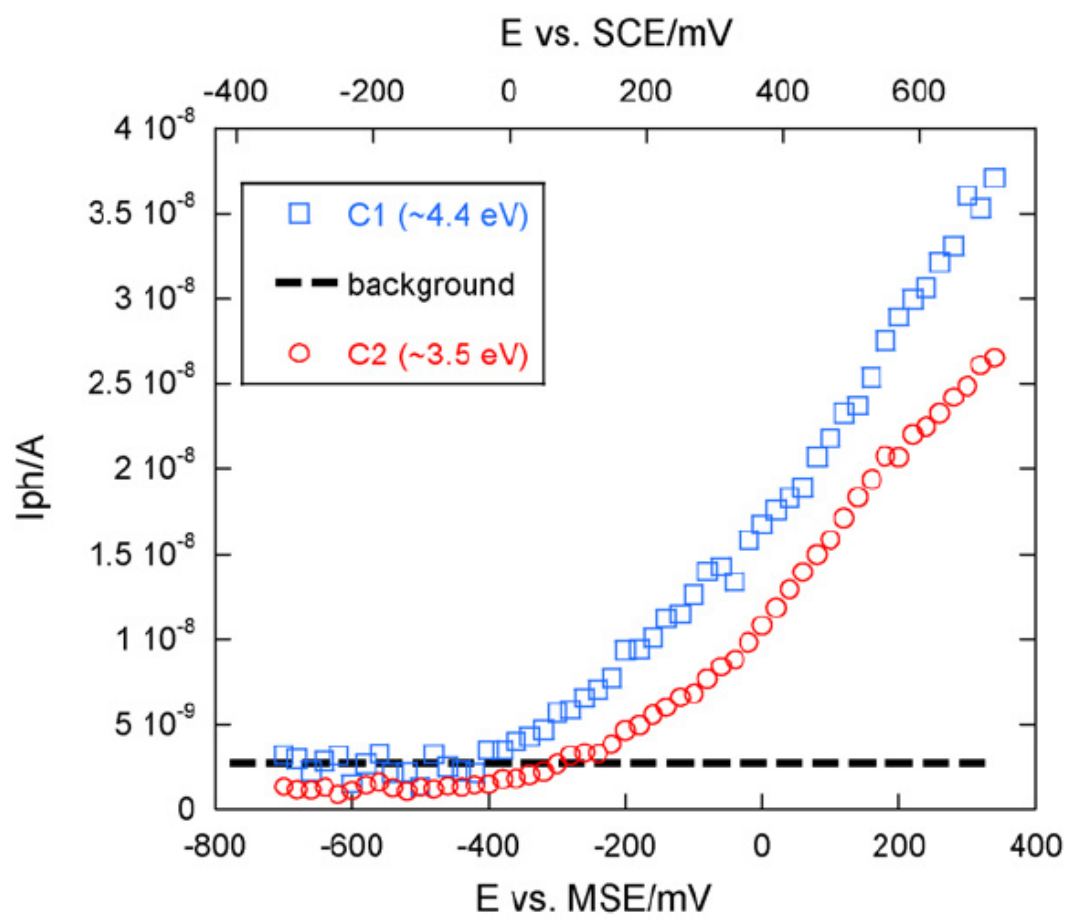

Figure 9: Photocurrent intensity in function of potential obtained for a sample corroded $858 \mathrm{~h}$ in $P$ WR primary medium for two different light energies corresponding to $\mathrm{C} 2(\sim 3.5 \mathrm{eV})$ and to $\mathrm{C} 1(\sim 4.4 \mathrm{eV})$.

It is also possible to compare these results with those obtained for the same oxide formed at high temperature in gaseous atmosphere. At high temperature, $\mathrm{Cr}_{2} \mathrm{O}_{3}$ can be both n-type and p-type semi-conductor [30] and [42]. As seen in Section III.1.2 and particularly in Figure 5, $\mathrm{NiCr}_{2} \mathrm{O}_{4}$ formed at high temperature presents also a mixed conductivity (n-type and p-type). This semiconduction change for a same oxide formed in different conditions has to be linked to the decrease of the oxidizing power between the aqueous hydrogenated water (very weak equivalent oxygen pressure) and a gas phase rich in oxygen. Indeed, in the case of an oxide layer growth, whose kinetic is controlled by diffusion, and for weak oxidizing conditions, the n-type component, which is independent of the activity of the oxygen [43], is favoured.

The shape of the curves represented in Figure 9 can also give information on the defects present in the oxide layers. The oxide layers are polycrystalline and contain structural defects such as grain boundaries or dislocations. These defects play the role of localized states in the gap and so act as recombination centres for the charge carriers [15] and [44]. In Figure 9, an increase of the photocurrent vs. potential is observed for potentials higher than approximately $-250 \mathrm{mV} / \mathrm{MSE}$ and $-400 \mathrm{mV} / \mathrm{MSE}$ for $\mathrm{Cr}_{2} \mathrm{O}_{3}$ and for the sum of $\mathrm{Cr}_{2} \mathrm{O}_{3}$ and the mixed 
chromite, respectively. This increase, according to the model of Marfaing [45] and to the experimental results published by Wouters et al. [15], is characteristic of a semiconductor containing a strong quantity of metallurgical defects, i.e. of oxides which contain a significant density of structural defects (like grain boundaries and dislocation).

The semiconduction type of the nickel hydroxides and/or the nickel ferrite has not been characterised but the results presented in Figure 6 are coherent with a "global" n-type semiconduction scheme. It is therefore supposed that nickel hydroxide and/or nickel ferrite behaves as an n-type semi-conductor.

\section{III.4. Surface distribution of the oxides}

The MPEC experiments were performed in order to characterise the oxide distribution along the layer with the achievement of photocurrent images if the gap corresponding to the oxide was accessible. The laser of the experimental device was not able to investigate a gap superior to $3.7 \mathrm{eV}$. The chromite repartition has therefore not been studied.

The photocurrent images presented in Figure 10 were performed with an alloy 690 sample corroded for different durations (66 h, $406 \mathrm{~h}$ and $858 \mathrm{~h}$ ) in PWR simulated conditions. They were obtained for a wavelength equal to $351 \mathrm{~nm}$, that is to say an energy of $3.5 \mathrm{eV}$ and are then representative of the $\mathrm{Cr}_{2} \mathrm{O}_{3}$ distribution. The average intensity of the photocurrent increases with the oxidation duration which means an increase in the quantity of $\mathrm{Cr}_{2} \mathrm{O}_{3}$ formed. Except in the case of the sample corroded during $66 \mathrm{~h}$, the images in photocurrent are roughly uniform on the whole analysed surface, which indicates a global homogenous distribution of $\mathrm{Cr}_{2} \mathrm{O}_{3}$. Nevertheless some fluctuations have been observed on every picture, which are due to some heterogeneity in terms of quantity of $\mathrm{Cr}_{2} \mathrm{O}_{3}$ or in terms of defects quantity in oxide.

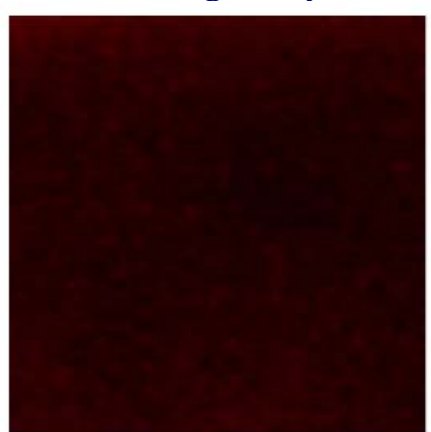

(a)

$200 \times 200 \mu \mathrm{m}^{2}$

point spacing of $1 \mu \mathrm{m}$

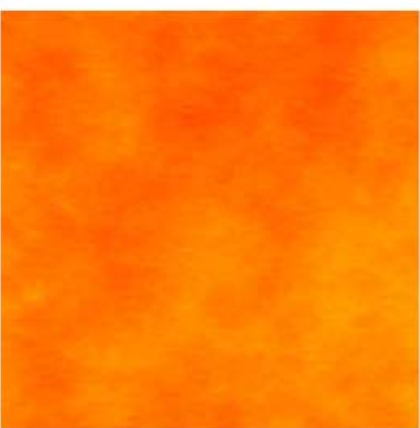

(b)

$500 \times 500 \mu \mathrm{m}^{2}$ point spacing of $1 \mu \mathrm{m}$

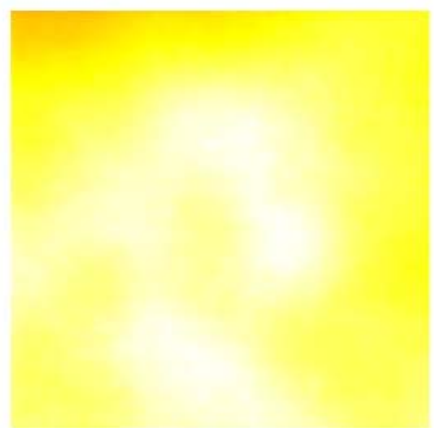

(c)

$200 \times 200 \mu \mathrm{m}^{2}$

point spacing of $0.5 \mu \mathrm{m}$

Figure 10: Photocurrent intensity mapping of alloy 690 samples corroded in PWR primary medium during (a) $48 \mathrm{~h}$, (b) $406 \mathrm{~h}$ and (c) $858 \mathrm{~h}$ performed at a potential of $50 \mathrm{mV} / \mathrm{MSE}$ and a wavelength of $351 \mathrm{~nm}(\mathrm{hv}=3.5 \mathrm{eV}$ ).

A photocurrent image was also carried out for a wavelength of $351 \mathrm{~nm}(3.5 \mathrm{eV})$ on an alloy 600 which had been exposed $858 \mathrm{~h}$ in PWR primary simulated medium (Figure 11). Figure 11a presents an image of the analysed zone obtained by optical microscopy, revealing the microstructure of alloy 600 under the oxide layer. Even if the amplitude of the photocurrent variations remains low (Figure 11b), these images reveal the presence of $\mathrm{Cr}_{2} \mathrm{O}_{3}$ within the layer formed on this alloy and enable to link the quantity of $\mathrm{Cr}_{2} \mathrm{O}_{3}$ formed and the crystalline orientation of the alloy grains. Consequently, preferential crystalline orientation should increase the growth rate of $\mathrm{Cr}_{2} \mathrm{O}_{3}$. This result is consistent with Refs. [13] and [14] where epitaxial relationships between alloy 690 and $\mathrm{Cr}_{2} \mathrm{O}_{3}$ nodules formed under PWR primary simulated conditions have been evidenced by HRTEM.The distribution of nickel hydroxide and/or nickel ferrite on alloy 690 corroded $858 \mathrm{~h}$ was also studied. The photocurrent mapping, presented in Figure 12, has been performed at a wavelength equal to $454.5 \mathrm{~nm}$ (or an energy of $2.7 \mathrm{eV}$ ). The presence of a photocurrent on the entire image shows that this compound is present on the whole surface. Nevertheless the photocurrent variation underlines a heterogeneous distribution of nickel hydroxide and/or nickel ferrite. 


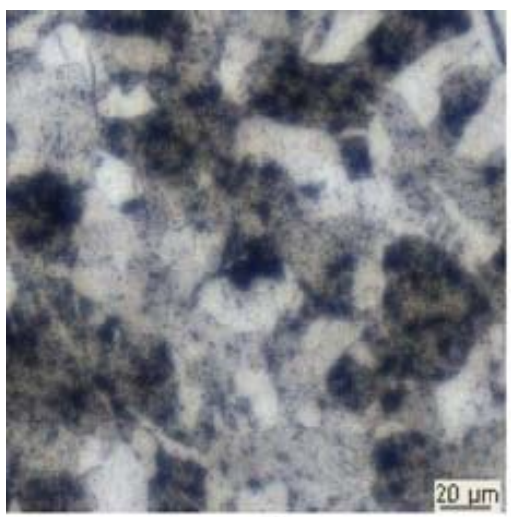

(a)

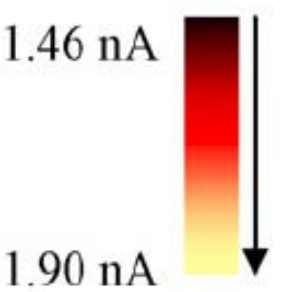

$200 \times 200 \mu \mathrm{m}^{2}$

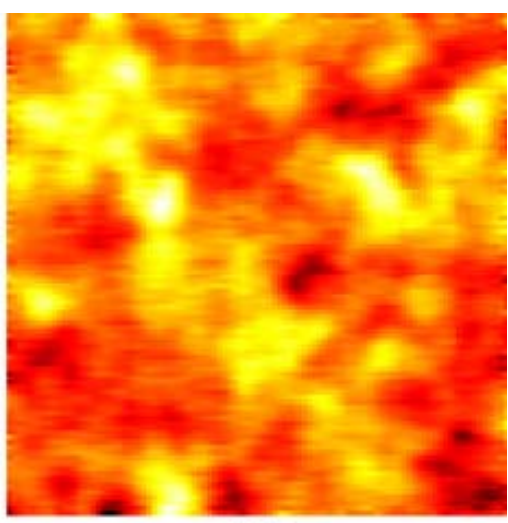

(b)

\section{$200 \times 200 \mu \mathrm{m}^{2}$ point spacing of $1 \mu \mathrm{m}$}

Figure 11: Optical image (a) and associated photocurrent intensity mapping (b) of alloy 600 sample corroded in $P W R$ primary medium during $858 \mathrm{~h}$ performed with a potential of $50 \mathrm{mV} / \mathrm{MSE}$ and a wavelength of $351 \mathrm{~nm}$ $(h v=3.5 \mathrm{eV})$.
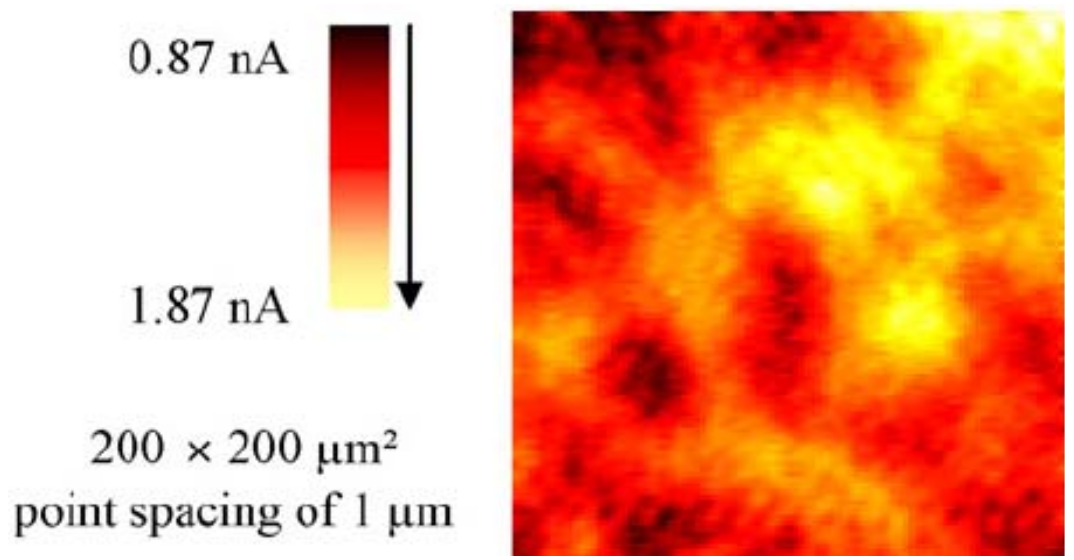

Figure 12: Photocurrent intensity mapping of alloy 690 samples corroded in PWR primary medium during $858 \mathrm{~h}$ performed with a potential of $50 \mathrm{mV} / \mathrm{MSE}$ and a wavelength of $454.5 \mathrm{~nm}(\mathrm{hv}=2.7 \mathrm{eV})$.

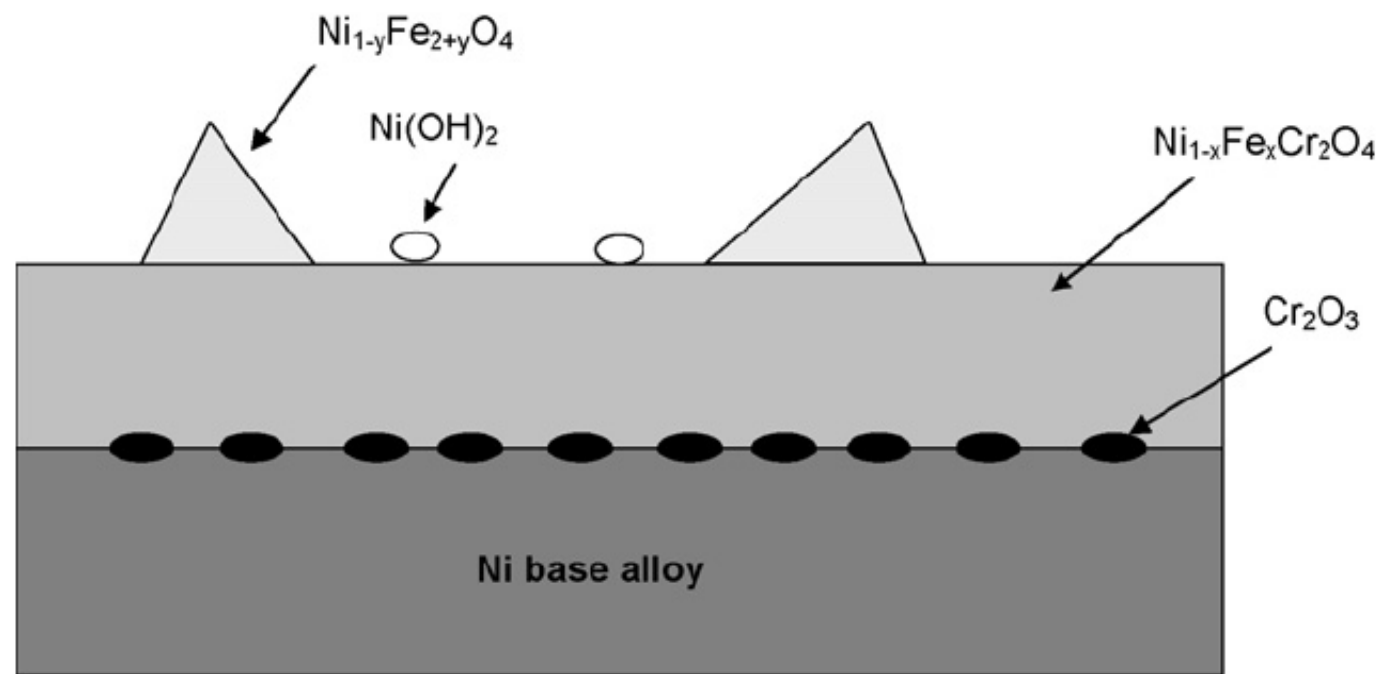

Figure 13: Scheme of the oxide film formed on nickel base alloy in PWR primary medium. 


\section{Discussion}

The photoelectrochemical characterisation of oxide layers formed on nickel base alloys in simulated primary water conditions of PWR enables to conclude to the presence of three or four different phases and to determine some properties of these phases (semiconduction type, distribution).

The major oxide is a spinel structure which corresponds to the global chemical formula $\mathrm{Ni}_{1-x} \mathrm{Fe}_{x} \mathrm{Cr}_{2} \mathrm{O}_{4}$. The experimental determination of the band gap of this phase, of $\sim 4.1 \mathrm{eV}$, has been evidenced for the first time in this work. The spinel is an n-type semi-conductor. It has to be noted that the spinel obtained by oxidation under air at high temperature $\left(900^{\circ} \mathrm{C}\right)$ has both n-type and p-type semi conduction properties. A decrease of the formation temperature of this oxide has therefore for consequence to change its semiconducting properties. This characteristic permits to determine which kind of defect is able to diffuse in the oxide layer (see below). It has not been possible to study the surface repartition of this spinel in the oxide layer by MPEC because of the wavelength accessible with the laser used. Nevertheless, since it is the major constituent of the layer and since the oxide layer acts as a protective structure, it can easily be supposed that the spinel chromite constitutes a continuous phase in the oxide structure. This was confirmed locally by TEM characterisation [13] and [14].

The second oxide, which has been identified in this study, is the chromia $\left(\mathrm{Cr}_{2} \mathrm{O}_{3}\right)$, exhibiting two indirect transitions (at $\sim 2.9 \mathrm{eV}$ and $\sim 3.5 \mathrm{eV}$ ). As for the spinel structure the semiconducting properties have been studied underlying an n-type semiconducting structure. This oxide is present on the whole surface of the alloy. However previous study by TEM highlights that this phase was present in the shape of nodules localized at the interface between the alloy and the chromite [13] and [14]. Using the MPEC technique enables to analyse a larger surface (typically $200 \mu \mathrm{m} \times 200 \mu \mathrm{m}$ ) to conclude that these nodules are quasi-homogeneously dispersed at the interface. It can be highlighted that the observation of a continuous photocurrent image is not inconsistent with HRTEM observations [13] and [14], which enhanced a discrete repartition of $\mathrm{Cr}_{2} \mathrm{O}_{3}$ nodules. In fact, the nodules of chromia observed by TEM have a size of few nanometres and the lateral resolution of the MPEC image realized here is about $0.5^{-1} \mu \mathrm{m}$. That is why quasi-homogeneously dispersion of $\mathrm{Cr}_{2} \mathrm{O}_{3}$ nodules leads to a continuous photocurrent image. Moreover a link has been evidenced between the crystalline orientation of the alloy grains and the rate of nucleation or growth of the $\mathrm{Cr}_{2} \mathrm{O}_{3}$ nodules.

The third identified contribution, whose gap is roughly $2.2 \mathrm{eV}$, could correspond to nickel hydroxide and/or nickel ferrite. According to the literature data [35] and [36] related to the band gap value of nickel ferrite, it has to be underlined that two cases must be distinguished: either the gap of this phase is greater than $5 \mathrm{eV}$ (as mentioned in Ref. [36]) and is therefore not achievable with this experimental device, or the gap of this phase is $\sim 2.2 \mathrm{eV}$ (as given in Ref. [35]) and its signal is mixed with the nickel hydroxide contribution.

Nevertheless, previous studies have shown that nickel hydroxide [1], [7], [10], [13] and [14], nickel ferrite (chemical formulae: Ni1-yFe2+yO4) [2], [3], [6], [8], [9], [11], [13] and [14], or nickel hydroxide and nickel ferrite [13] and [14], were present at the outer surface of the oxide formed on nickel base alloys in PWR simulated conditions, resulting from precipitation phenomena.

This third contribution is present on the entire surface. However the HRTEM observation [13] and [14] enables to conclude that the distribution of nickel hydroxide and nickel ferrite (under the form of polyhedral crystallites) is not continuous.

Finally, the results obtained in this study, by PEC and MPEC (where the analysed surface is respectively around $0.8 \mathrm{~cm}^{2}$ and $200 \mu \mathrm{m} \times 200 \mu \mathrm{m}$ ), enable to generalize the local observations obtained by TEM and HRTEM [13] and [14] to a scale which is coherent with the description of a phenomenon of generalized corrosion. The sum of these results enable to confirm the structure of the oxide layer shown in Figure 13 and already supposed in Refs. [13] and [14] from local observations.

Moreover the semiconducting properties of the oxides (chromite and $\mathrm{Cr}_{2} \mathrm{O}_{3}$ ) enable to make some assumption on the mechanism of oxidation and release. The two protective oxides 
formed in PWR primary water have been identified as n-type semiconductor. As a consequence, the point defects associated to this kind of semiconducting properties are charged positively. It can be on one hand some defects in substitution in the anionic sublattice such as oxygen vacancies or hydroxide ions in substitution and on the other hand metal cations in interstitial position in the cationic sub-lattice. In order to obtain a complete description of the growth mechanism of protective oxide formed on nickel base alloys exposed to PWR primary simulated medium, these results must be compared with tracers and markers experiments previously realized [40]. These latter experiments highlight an anionic growth of the protective oxide scale, composed of chromite and $\mathrm{Cr}_{2} \mathrm{O}_{3}$.

By comparing the results published in Ref. [40] and the semiconducting properties of chromite and $\mathrm{Cr}_{2} \mathrm{O}_{3}$ determined in this work, it can be concluded that the growth of these two oxides results from the diffusion of oxygen vacancies or hydroxide ions in substitution in the anionic sub-lattice. It can be also pointed out that the release of Ni and Fe cations in the PWR primary medium is due to diffusion through the protective oxide scale. In respect with this oxide semiconducting properties, the point defects responsible for this diffusion seem to be interstitial cations in the cationic sub-lattice.

In the study of semiconducting properties, another interesting point is the variation of photocurrent in function of the applied potential. These types of variations for $3.5 \mathrm{eV}$ and $4.4 \mathrm{eV}$ (which respectively correspond to chromia and to the sum of chromia and chromite) demonstrate a high level of recombination centres in these semiconductor phases which highlights a high density of defects like grain boundaries or dislocations [15] and [44]. These data could be important in the aim of a complete description of the growth mechanism of this oxide scale, where this type of defects can play a key role in diffusion processes.

\section{Conclusions}

The photoelectrochemical methods (PEC and MPEC) have been used, on the one hand, to characterise the nature of the different oxides forming the multilayer structure resulting from the exposition of nickel base alloys to PWR primary simulated medium, and on the other hand, to obtain some data about the semiconducting properties of both oxides composing the protective part of the multilayer structure.

As preliminary part of this work, the band gap energy of nickel chromite has been measured and is equal to $\sim 4.1 \mathrm{eV}$.

The multilayer oxide formed during corrosion of nickel base alloys in PWR primary simulated medium has been locally characterised by advanced TEM techniques in a previous work [13] and [14]. The results obtained by PEC and MPEC in this work enable to generalize the local observations obtained HRTEM to a scale which is coherent with the description of a phenomenon of generalized corrosion.

The internal and protective layer can be divided into a continuous film of $\mathrm{Ni}_{(1-x)} \mathrm{Fe}_{x} \mathrm{Cr}_{2} \mathrm{O}_{4}$, and nodules of $\mathrm{Cr}_{2} \mathrm{O}_{3}$ quasi-uniformly dispersed along the alloy/oxide interface. Moreover, the rate of nucleation or growth of the $\mathrm{Cr}_{2} \mathrm{O}_{3}$ nodules seems to be slightly influenced by the crystalline orientation of the alloy grains.

The external layer is composed of nickel hydroxide and nickel ferrite heterogeneously dispersed on the surface.

Moreover, the chromia and chromite formed in PWR primary water have been identified as ntype semiconductors. By comparing these results with those formerly obtained by tracers and markers experiments, it can be proposed, on the one hand, that the point defects associated to the growth of the protective oxide scale are in substitution in the anionic sub-lattice, and on the other hand, that the diffusion of interstitial cations in the cationic sub-lattice are responsible for the release in the primary fluid.

\section{References}

[1] N.A. McIntyre, D.G. Zetaruk and D. Oven, J. Electrochem. Soc. 126 (1979), p. 750.

[2] L. Guinard, O. Kerrec, D. Noel, S. Gardey and F. Coulet, Nucl. Energy 36 (1997), p. 19. 
[3] F. Carette, M.C. Lafont, G. Chataignier, L. Guinard and B. Pieraggi, Surf. Interface Anal. 34 (2002), p. 135.

[4] F. Carette, L. Guinard and B. Pieraggi, Proceedings of International Conference on Water Chemistry of Nuclear Reactor Systems Avignon, France, April 22-26 (2002).

[5] A. Machet, A. Galtayries, P. Marcus, P. Combrade, P. Jolivet and P. Scott, Surf. Interface Anal. 34 (2002), p. 197.

[6] F. Carette, M.C. Lafont, L. Legras, L. Guinard and B. Pieraggi, Mater. High Temp. 20 (2003), p. 581.

[7] A. Machet, A. Galtayries, S. Zanna, L. Klein, V. Maurice, P. Jolivet, M. Foucault, P. Combrade, P. Scott and P. Marcus, Electrochim. Acta 49 (2004), p. 3957.

[8] S. Gardey, PhD Thesis, University of Paris 6, France, 1998.

[9] F. Carette, PhD Thesis, Polytechnic National Institute of Toulouse, France, 2002.

[10] A. Machet, PhD Thesis, University of Paris 6, France, 2004

[11] F. Delabrouille, PhD Thesis, Polytechnic National Institute of Toulouse, France, 2004.

[12] A. Machet, A. Galtayries, S. Zanna, P. Jolivet, M. Foucault, P. Combrade, P. Scott and P. Marcus, Proc. EUROCORR 2004 Nice, France, September 12-16 (2004).

[13] M. Sennour, L. Marchetti, F. Martin, S. Perrin, R. Molins, M. Pijolat, J. Nucl. Mater., 2010, doi:10.1016/j.jnucmat.2010.05.010

[14] M. Sennour, L. Marchetti, S. Perrin, R. Molins, M. Pijolat and O. Raquet, Mater. Sci. Forum 595-598 (2008), p. 539.

[15] Y. Wouters, L. Marchetti, A. Galerie and J.-P. Petit, Corros. Sci. 50 (2008), p. 1122.

[16] A. Galtayries, A. Machet, S. Zanna, P. Jolivet, M. Foucault, P. Combrade, P. Scott and P. Marcus, Proc. Passivity 9: 9th International Symposium on the Passivation of Metals and Semiconductors and the Properties of Thin Oxide Layers Paris, France, June 27July 1 (2005).

[17] M.-R. De Nicola, A. Galerie and J.-P. Petit In: S.B. Newcomb and M.J. Bennett, Editors, Microscopy of Oxidation II, Institute of Materials, Minerals and Mining, London (1993), p. 338.

[18] Y. Wouters, A. Galerie, L. Antoni and J.-P. Petit In: S.B. Newcomb and J.A. Little, Editors, Microscopy of Oxidation III, Ashgate Publishing Limited, London (1997), p. 418.

[19] Y. Wouters, G. Bamba, A. Galerie, M. Mermoux and J.P. Petit, Mater. Sci. Forum 461464 (2004), p. 839.

[20] Y. Wouters, L. Marchetti, A. Galerie, P. Bouvier and J.P. Petit In: R. Oltra, V. Maurice, R. Akid and P. Marcus, Editors, Local Probe Techniques for Corrosion Research (EFC 45), Woodhead Publishing Limited, Cambridge (2007), p. 172.

[21] V.N. Antonov, B.N. Harmon and A.N. Yaresko, Phys. Rev. B: Condens. Matter 67 (2003), p. 024417.

[22] M.A. Butler and D.S. Ginley, J. Electrochem. Soc. 125 (1973), p. 228.

[23] F. Di Quarto, S. Piazza and C. Sunseri, Mater. Sci. Forum 192-194 (2) (1995), p. 633.

[24] S. Piazza, M. Sperandeo, C. Sunseri and F. Di Quarto, Corros. Sci. 46 (2004), p. 831.

[25] F. Di Quarto, C. Sunseri, S. Piazza and M.C. Romano, J. Phys. Chem. B 101 (1997), p. 2519.

[26] Di Quarto, M.C. Romano, M. Santamaria, S. Piazza and C. Sunseri, Russ. J. Electrochem. 36 (2000), p. 1203.

[27] M.K. Carpenter and D.A. Corrigan, J. Electrochem. Soc. 136 (1989), p. 1022.

[28] O. Sunseri, S. Piazza and F. Di Quarto, J. Electrochem. Soc. 137 (1990), p. 2411.

[29] K.P. Lillerud and P. Kofstad, J. Electrochem. Soc. 127 (1980), p. 2410.

[30] E.W.A. Young, J.H. Gerretsen and J.H.W. de Witt, J. Electrochem. Soc. 134 (1987), p. 2257.

[31] S. Henry, J. Mougin, Y. Wouters, J.P. Petit and A. Galerie, Mater. High Temp. 17 (2000), p. 231.

[32] M.P. Dare-Edwards, J.B. Goodenough, A. Hamnett and N.D. Nicolson, J. Chem. Soc., Faraday Trans. 2 (77) (1981), p. 643.

[33] G. Dagan, W.M. Shen and M. Tomkiewicz, J. Electrochem. Soc. 139 (7) (1992), p. 1855. 
[34] Y. Wouters, PhD Thesis, Polytechnic National Institute of Grenoble, France, 1996.

[35] S. Balaji, R. Kalai Selvan, L. John Berchmans, S. Angappan, K. Subramanian and C.O. Augustin, Mater. Sci. Eng. B 119 (2005), p. 119.

[36] M. Srivastava, A.K. Ojha, S. Chaubey and A. Materny, J. Alloys Compd. 481 (2009), p. 515.

[37] F. Di Quarto, S. Piazza and C. Sunseri In: P. Marcus, B. Baroux and M. Keddam, Editors, Modification of Passive Films (EFC 12), Maney Publishing, London (1994), p. 76.

[38] U. Stimming, Electrochim. Acta 31 (1986), p. 415.

[39] G. Calvarin, A.M. Huntz and R. Molins, Mater. High Temp. 17 (2000), p. 257.

[40] L. Marchetti, S. Perrin, O. Raquet and M. Pijolat, Mater. Sci. Forum 595-598 (2008), p. 529.

[41] Z. Szklarska-Smialowska, W.-K. Lai and Z. Xia, Corrosion 46 (1990), p. 853.

[42] A. Galerie, S. Henry, Y. Wouters, M. Mermoux, J.-P. Petit and L. Antoni, Mater. High Temp. 22 (2005), p. 105.

[43] P. Sarrazin, A. Galerie and J. Fouletier, Mechanisms of High Temperature Corrosion: A Kinetic Approach, Trans Tech Publications Ltd., Zurich, Switzerland (2008).

[44] A. Broniatowski In: CNRS, Editor, Les joints de grains dans les matériaux,, Les éditions de la physique, Les Ulis (1984), p. 409.

[45] Y. Marfaing, Proc. Ecole d'hiver du CNRS: L'interface semiconducteur/electrolyte Aussois, France, December 9-15 (1984). 